\title{
Herbs for Oro-Dental Health: Nature's Own Remedy
}

\begin{tabular}{|c|}
\hline ODE \\
\hline 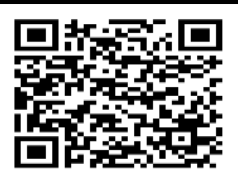 \\
\hline
\end{tabular}

\section{SUNYANA BHAGAT ID}

Since ages, man has been using herbal medications for prevention and cure of countless diseases. Before the start of civilization, medicines were probably available in the natural forms. The use of herbs for oro-dental care can be rooted from ancient civilizations. Over the past few years, herbal medications have been into consideration across the globe mainly due to their high safety profile as compared to modern medicines. Most of herbal derivatives have medicinal properties mainly being antiinflammatory, antimicrobial, antiseptics, antibacterial and anti-oxidant. Some also help to control plaque, reduce irritation and tackle infection related to oral cavity with very few adverse reactions as compare to modern day medicines. Future research should be carried out to study the action mechanism, efficacy and safety of these abundant natural resources of plant origin. The review highlights the herbs which can be used for preventing and curing dental diseases.

KEYWORDS: Herbs, Dentistry, Herbal Medicines, Oral Health

\section{INTRODUCTION}

Plants sources have been used since long treatment of many diseases in the Eastern region countries. ${ }^{1}$ and have also been able to draw attention in United states of America, Europe and Japan. ${ }^{1-3}$ Herbal extracts are being used in traditional medicine for thousands of years. ${ }^{4}$ Herbal drugs are those that originate from the plants and are used to treat diseases attaining or maintaining the condition of improved health.,5 The roots of traditional medicines are grounded deep in the history and these have been used in India since times immemorial. There are many medicinal systems in India, the most popular being the Ayurveda. The traditional healers in India use around 2,500 plant species and a 100 species of plants act as a regular source of medication. ${ }^{7}$ The herbal medicines are widely used for the treatment of systemic diseases. They contain compounds called phytochemicals that can be considered as an effective substitute to antibiotics and a promising approach towards preventing and treating for infections of oral origin. ${ }^{8}$ Moreover, the economic benefits in the treatment of various diseases are also considerable if indigenous medicines are developed and medicinal plants are used. ${ }^{9}$

Oro-dental disorders directly impact the oral health related quality of life. More than 750 species of bacteria are found in the oral cavity and a few of these lead to causation and progression of oral diseases thus having a detrimental effect on oral health..$^{10}$ The anti-inflammatory medicines, analgesics and antibiotics being used to treat dental diseases are reported to have countless adverse reactions ranging from mild rash to life-threatening anaphylaxis and DRESS syndrome. Antibiotic resistance is a universal issue. Because of valid reasons like safety concerns, drug resistance and high costs of synthetic medication, natural and herbal medicaments can be considered as an upcoming substitute to modern day medicines.

The traditional medical systems have described many procedures for maintenance of good oral hygiene Twigs, most commonly those of neem tree (botanical name azadirachta indica) have been considered as a brushing tool since ages and are still being regularly used in rural areas. Although it has got a bitter taste, it contains volatile oils which stimulate blood circulation and tannins which help in cleaning of gums and other soft tissues of the oral cavity. It also helps to inhibit the growth of S. Mutans. These neem twigs have got antiseptic, astringent, and antibacterial properties."

Cinnamaldehyde from cinnamon has got antifungal and antibacterial properties, which help in decreasing the chances of infections and help prevent dental caries and halitosis." A few chewing gums available in the market have got cinnamon essence which acts as a flavouring agent due to its refreshing taste. 
Cinnamon has got beneficial effects on oral health and can be used to treat toothache, oral infections, and halitosis. ${ }^{12}$

Triphala is a combination of herbs with three important ayurvedic components. It consists of Amalaka (botanical name Emblica officinalis), haritaki (botanical name Terminalia chebula) and bibheetaka (botanical name Terminalia bellirica). Triphala has got an anti-plaque and anti-caries effect mainly determined by its property to inhibit bio-film formation and aggregations of S. mutans. It has also got better antioxidant activity as compared to commercially available dentifrices. Triphala is also known to have anti-cancer properties. ${ }^{13}$

Green tea extract from Camellia sinensis is being used worldwide for weight loss. As it is reported to inhibit the growth of Streptococcus mutans due to its richness in catechins, it helps in improvement of dental health and also reduces the caries risk, helps in prevention of halitosis and decreases the risk and progression of cancers. ${ }^{14,15}$

Aloe vera has got antibacterial, antifungal and antiviral properties and is effective against Candida albicans, Streptococcus mutans, Lactobacillus acidophilus, Enterococcus faecalis, Prevotella intermedia, Peptostreptococcus anaerobius, Streptococcus pyogenes, Streptococcus faecalis and S. mitis. The plant contains a few anthraquinones which act against many bacteria, fungi and viruses and are also known to have analgesic properties. It can be placed as a medicament in periodontal pockets and helps in treating periodontitis. ${ }^{16-18}$

The Salvadora persica tree commonly known as Miswak tree, is popular for its importance in dentistry was established centuries ago. The chewing sticks of this plant were used in Babylonia, Greek and Roman empires and is still the common traditional toothbrush in many countries. Its use is popular in Islamic countries, probably due to some religious principal reason behind the same. The Meswak extract is also used in the formulation of toothpastes due to its antiplaque and antigingivitis activity. Gupta $\mathrm{P}$ et al in 2012 found comparable results in a study that was conducted to evaluate the antiplaque efficacy of a Meswak containing toothpaste and a conventional toothpaste. ${ }^{19}$ It is rich in tannins, vitamin C, sodium chloride, fluorides, chlorides, calcium oxalate, alkaloids, saponins, sulphur, flavonoids, salvadorine, silica, trimethylamine, and benzyl isothiocyanate (bactericidal in nature). These components, directly or in an indirect way help in prevention of plaque formation and dental caries. Some of these have antibacterial activity, a few help in strengthening of gingival tissue and inhibition of calculus formation while others provide protection against caries by forming a layer over the enamel. Miswak affects the $\mathrm{C}_{3} \mathrm{~T}_{3}$ fibroblasts and is an antibacterial agent for Streptococcus mutans. ${ }^{20}$

Tulsi (botanical name Ocimum sanctum), also known as holy basil contains tannins, carvacrol, essential oils, oleanolic acid, eugenol, ursolic acid, methyleugenol, rosmarinic acid, alpha caryophyllene, beta caryophyllene, methylchavicol, linalool and cineole. It can cure fever, pain, inflammation and ulcers, can stimulate immune system, has got antimicrobial and antihelminthic properties. It acts as a good and long lasting mouth freshener, disinfects the oral cavity and helps in decreasing the extent of periodontitis. It is known to cease the growth of precancerous lesions and cancers of oral origin. It has also got astringent properties that keep the gingival tissue firm preventing tooth mobility and also destroys the bacteria that may result in plaque, tooth decay and bad breath. ${ }^{21,22}$

Turmeric (botanical name Curcuma Longa) is a part of every kitchen. It has got antiinflammatory, antiseptic, antioxidant, antimutagenic, anticarcinogenic, antibacterial, antimicrobial, hepatoprotective, and immunostimulant properties. Turmeric includes volatile oils, monoterpenes, sesquiterpenes, zingiberene, curcumin and turmerone. Massaging the teeth with roasted, ground turmeric can help to remove pain and inflammation. ${ }^{5}$ Mali AM et al, conducted a study to check the antiplaque effect of $0.1 \%$ turmeric mouthwash and its effect on gingival inflammation and reported that turmeric mouthwash can be effectively used in prevention of plaque and treatment of gingivitis. ${ }^{23}$ Curcumin, a major constituent of turmeric may inhibit inflammation at molecular level. It has also got good antioxidant potential and works by neutralizing the free radicals and stimulating the body's antioxidant enzymes. It also can result in several changes at a molecular level that may be of great help in prevention and treatment cancer. ${ }^{24,25}$

Coriander has also got antiseptic properties mainly due to its component citronellol. It might also 
exhibit antimicrobial and antifungal, anti-ulcer properties and also helps in healing and prevention of bad breath. ${ }^{26}$

Countless herbal derivatives have got beneficial effects on the oral tissues, some of these are known and many yet to be discovered. Nature has provided us with remedies for every disease and disorder, the major concern is to unlock them, conduct trials regarding efficacy and collate data concerning adverse reactions associated with them.

\section{CONCLUSION}

The modern world is inclined towards the discovery of new compounds and treatment modalities, whereas stress should be laid on medicaments of herbal origin. These natural substitutes are better than the current treatments for oro-dental issues. There is a definite need to conduct more research on safety and efficacy profiles of herbal medicines for establishment of their therapeutic benefits, so that enough data is available for meta-analysis, leading to scientifically proven conclusions on the pharmacokinetics and pharmacodynamics of these medicines, eventually making human life happier and healthier with the help of natural resources.

\section{REFERENCES}

1. Hoseini HF, Fakhrzadeh H, Larijani B, Shikhsamani A. Review of anti-diabetic medicinal plant used in traditional medicine. J Med Plant 2006;5 Suppl 2:1-8.

2. Hartzell JF, Zysk KG. Health, science, and the spirit: Veda and Âyurveda in the Western world. J Altern Complement Med 1995;1:297-301.

3. Mattick CR. Stomatology - An intriguing blend of traditional Chinese medicine and Western-style dentistry. Br Dent J 1995;178:350-3.

4. Rabia A Abu. Urinary diseases and ethnobotany among pastoral nomads in the Middle East. Journal of Ethnobiology and Ethnomedicine.2005:1(4):1-4.

5. Chaturvedi TP. Uses of turmeric in dentistry: An update. Indian J Dent Res 2009;20:107-9.

6. Holetz FB, Ueda-Nakamura T, Dias Filho BP, Mello JC, Morgado-Díaz JA, Toledo CE, et al. Biological effects of extracts obtained from Stryphnodendron adstringens on Herpetomonas samuelpessoai. Mem Inst Oswaldo Cruz 2005;100:397-401.

7. Lev E. Ethno-diversity within current ethnopharmacology as part of Israeli traditional medicine A review. Journal of Ethnobiology and ethnomedicine.2006;2(4):1-12.

8. Kumar P, Ansari SH, Ali J. Herbal remedies for the treatment of periodontal disease - A patent review. Recent Pat Drug Deliv Formul 2009;3:221-8.

9. Azaizeh H, Fulder S, Khalil K, Said O. Ethnomedicinal knowledge of local Arab practitioners in the Middle East Region. Fitoterapia 2000;74:98-108.

10. Jenkinson HF, Lamont RJ. Oral microbial communities in sickness and in health. Trends Microbiol 2005;13:589-95.

11. Chatterjee A, Saluja M, Singh N, Kandwal A.To evaluate the antigingivitis and antipalque effect of an AzadirachtaIndica (Neem) mouthrinse on plaque induced gingivitis: A double-blind, randomized, controlled trial. J Indian SocPeriodontol 201115:398401.

12. Chaudhary SS, Tariq M, Zaman R, Imtiyaz S. The In vitro anti - acne activity of two unani drugs. Anc Sci Life 2013;33:35-8.

13. Jagadish L, Anand Kumar VK, Kaviyarasan V. Effect of Triphala on dental bio-film. Indian Journal of Science and Technology.2009;2:30-3.

14. Taylor PW, Hamtion-Miller JMT, Stapleton PD. Antimicrobial properties of green tea catechins, Food Sci Technol Bull 2005;2:71-81.

15. Suganuma M, Okabe S, Sueoka N, Sueoka E, Matsuyama S, et al. Green tea and cancer chemoprevention. Mutat Res 1999; 428: 339-44.

16. Kelmanson JE, Jäger AK, van Staden J. Zulu medicinal plants with antibacterial activity. J Ethnopharmacol 2000; 69: 241-6.

17. Bhat G, Kudva P, Dodwad V. Aloe vera: Nature's soothing healer to periodontal disease. J Indian Soc Periodontol 2011;15:205-9.

18. George D, Bhat SS, Antony B. Comparative evaluation of the antimicrobial efficacy of Aloe vera tooth gel and two popular commercial toothpastes: An in vitro study. Gen Dent 2009;57:238-41.

19. Gupta P, Agarwal N, Anup N, Manujunath BC, Bhalla A. Evaluating the anti-plaque efficacy of meswak (Salvadora persica) containing dentifrice: A triple blind controlled trial. J Pharm Bioallied Sci 2012;4:282-5.

20. Ayub F, Thomas B, Paulaian B, Emil J. Herbs and dental caries - A review. Univ J Pharm 2013;2:18-21.

21. Agarwal P, Nagesh L. Comparative evaluation of efficacy of $0.2 \%$ Chlorhexidine, Listerine and Tulsi extract mouth rinses on salivary Streptococcus mutans count of high school children--RCT. Contemp 
Clin Trials 2011; 32: 802-8.

22. Sumit B, Geetika A. Therapeutic benefits of Holy Basil (Tulsi) in general and oral medicine: A Review. Int J Res Ayur Pharm 2012;3(6): 761-4.

23. Mali AM, Behal R, Gilda SS. Comparative evaluation of $0.1 \%$ turmeric mouthwash with $0.2 \%$ chlorhexidine gluconate in prevention of plaque and gingivitis: A clinical and microbiological study. J Indian Soc Periodontol 2012;16:386-91.

24. Mortellini R, Foresti R, Bassi R, Green CJ. Curcumin, an antioxidant and anti-inflammatory agent, induces heme oxygenase-1 and protects endothelial cells against oxidative stress. Free Radic Biol Med 2000; 28:1303-2.

25. Rao CV, Rivenson A, Simi B, Reddy BS. Chemoprevention of colon carcinogenesis by dietary curcumin, a naturally occurring plant phenolic compound. Cancer Res 1995;55:259-6.

26. Chithra V, Leelamma S. Hypolipidemic effect of coriander seeds Coriandrum sativum): mechanism of action, Plant Foods Hum Nutr 1997;51(2):167-72. 